\title{
Determination of cordycepin content of Cordyceps militaris recombinant rice by high performance liquid chromatography
}

\author{
Xuesong Wang ${ }^{1}$, Fang Liu ${ }^{1}$, Fang Li ${ }^{1,2}$, Hongyan Cai ${ }^{1}$, Wei Sun ${ }^{1}$, Xuan Chen ${ }^{1}$, \\ Hong $\mathrm{GaO}^{3}$, Wangyang Shen ${ }^{1,2 *}$ \\ ${ }^{1}$ School of Food Science and Technology, Wuhan Polytechnic University, ${ }^{2}$ Hubei Collaborative Innovation Center for \\ Processing of Agricultural Products, Wuhan 430023, ${ }^{3}$ Institute of Agri-products processing and Nuclear-Agricultural \\ Technology, Hubei Academy of Agricultural Sciences, Wuhan 430064, China
}

*For correspondence: Email: whwangyangshen@126.com; Tel: +86-27- 83924790; Fax: +86-27-83924790

Received: 31 May 2016

Revised accepted: 13 September 2016

\begin{abstract}
Purpose: To assess the suitability of high performance liquid chromatography (HPLC) for the determination of cordycepin content of Cordyceps militaris recombinant rice

Methods: Cordyceps militaris recombinant rice was made by mixing brown rice with artificial Chinese caterpillar fungus culture medium powder using twin-screw extrusion technology. Cordycepin content was determined by reversed-phase HPLC with water:acetonitrile (95:5, v/v) as mobile phase, detection wavelength of $260 \mathrm{~nm}$, and flow rate of $1.0 \mathrm{~mL} / \mathrm{min}$.

Results: Cordycepin contents showed good linearity in the range of $1-50.0 \mu \mathrm{g} / \mathrm{mL}\left(r^{2}=0.9996\right)$, and while recovery ranged from 103.2 to $109.9 \%$. Relative standard deviation (RSD), precision and repeatability $R S D$ was $2.38,0.76$ and $1.46 \%$, respectively.

Conclusion: The HPLC method is simple, fast, accurate and reproducible. It is suitable for determination of cordycepin content of artificial Chinese caterpillar fungus culture medium and brown rice recombinant rice.
\end{abstract}

Keywords: Recombinant rice, Cordycepin, Chinese caterpillar fungus, Aweto, Cordyceps militaris

\begin{abstract}
Tropical Journal of Pharmaceutical Research is indexed by Science Citation Index (SciSearch), Scopus, International Pharmaceutical Abstract, Chemical Abstracts, Embase, Index Copernicus, EBSCO, African Index Medicus, JournalSeek, Journal Citation Reports/Science Edition, Directory of Open Access Journals (DOAJ), African Journal Online, Bioline International, Open-J-Gate and Pharmacy Abstracts
\end{abstract}

\section{INTRODUCTION}

Cordyceps militaris, also called North Aweto, is commonly known as Chinese caterpillar fungus. Aweto possesses significant medicinal value, which has led to increases in its domestic and foreign demand [1,2]. However, production of natural Cordyceps militaris is decreasing yearly due to poor growth conditions, thereby resulting in shortfalls in supply and inability to meet increasing demand $[3,4]$. At present, Aweto substitutes are made by artificial cultivation of the fruiting body of Cordyceps militaris, using a fast- growing biotechnological approach [5,6]. Research has shown that the solid medium of Chinese caterpillar fungus also contains cordycepin, sometimes even at higher levels than the fruiting body $[7,8]$.

Chinese caterpillar fungus has many important bioactive substances, such as nucleosides (for example, cordycepin), polysaccharides and cordycepic acid (mannitol) [9,10]. Cordycepin can be used to improve immune function, and for treating cancer, leukemia, chronic bronchitis, pulmonary heart disease, hyperlipidemia, 
hyperglycemia, and also as anti-aging agent [11]. Cordyceps polysaccharides may be used as antitumor, anti-radiation and immune-boosting compounds. Studies have shown that cordyceps D-mannitol has diuretic, anti-asthmatic, expectorant, and antioxidant properties [12].

In this study, Cordyceps militaris recombinant rice was made by twin screw extruder [16] with cordyceps culture medium and brown rice as raw materials, and a reversed-phase HPLC method was developed for the analysis of cordycepin content of the recombinant rice[3,14].

\section{EXPERIMENTAL}

\section{Chemicals and samples}

Chromatographic grade acetonitrile was purchased from Tianjin Kermel Chemical Reagent Company Ltd., China.

Cordycepin standard (C10H13N5O3) was obtained from Meilun Biological. Chinese Caterpillar fungus culture medium was a product of Hubei Academy of Agricultural Sciences (Wuhan, China). Experimental water was ultrapure water, and the other reagents used in the experiment were all analytically pure.

\section{Chromatographic conditions}

HPLC analysis was carried out in high performance liquid chromatograph equipment (Agilent Technologies) with a $250 \mathrm{~mm}$ eighteen alkyl bonded phase silica column of internal diameter $4.6 \mathrm{~mm}$.

Mobile phase was acetonitrile:water in a volume ratio of 5:95, and flow rate was $1 \mathrm{~mL} / \mathrm{min}$. Sample injection volume was $10 \mu \mathrm{L}$. Analysis was done at a column temperature of $35^{\circ} \mathrm{C}$ and wavelength of $260 \mathrm{~nm}$ [15].

\section{Codycepin standard curve}

A $100 \mu \mathrm{g} / \mathrm{mL}$ standard solution of cordycepin was prepared by dissolving $10 \mathrm{mg}$ of cordycepin in $100 \mathrm{~mL}$ mobile phase (5:95 v/v acetonitrile: water) with shaking. Serial dilutions of the standard were prepared and subjected to HPLC analysis to determine cordycepin concentrations. Peak times, peak heights, and peak areas of the standard cordycepin concentrations were determined. Data obtained were used for plotting standard curve and for deriving linear regression equation.

\section{Production process for cordyceps recombinant rice}

The procedure used for production of recombinant rice is summarised in Scheme 1 [16].

Conditions for formation of cordyceps recombinant rice were: content of cordyceps in culture medium: $20 \%$; total moisture content: 40 \%; screw speed; 250 rpm; barrel temperature: 80 ${ }^{\circ} \mathrm{C}$.

\section{Preparation of rice extract}

Rice sample $(0.5 \mathrm{~g})$ was uniformly ground and placed in a $100-\mathrm{mL}$ volumetric flask containing about $80 \mathrm{~mL}$ of water. It was then subjected to ultrasonic extraction for $3 \mathrm{~h}$, after which $1 \mathrm{~mL}$ was centrifuged at the speed of $4000 \mathrm{rpm}$. The supernatant fluid was filtered through a $0.45 \mu \mathrm{m}$ microporous membrane (Tianjin Jinteng Laboratory Equipment Co., Ltd.), and the filtrate was used for HPLC analysis. Analysis was repeated six times, and relative standard deviation was obtained. To test for recovery, 5 samples of the cordyceps culture medium were each spiked with $10 \mathrm{~mL}$ of $5 \mathrm{ug} / \mathrm{mL}$ cordycepin, and the recovery of added codycepin via HPLC was determined. Average peak area and RSD were calculated.

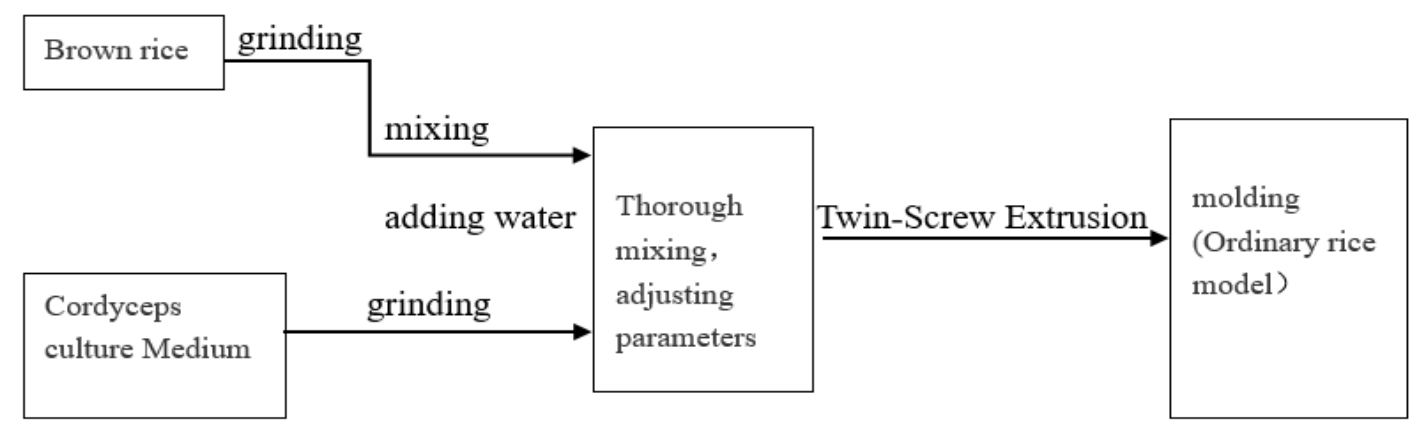

Scheme 1: Outline of the production of recombinant rice 


\section{RESULTS}

The peak time, peak area and peak height of the six concentrations of cordycepin standard solution are shown in Table 1. The standard curve was linear, with a good linear correlation (regression equation was $y=67.397 x-3.6872$ and regression coefficient of $R^{2}=0.9992$ ). Cordycepin concentrations of cordyceps culture medium and cordyceps recombinant rice were 14.13 and $2.56 \mu \mathrm{g} / \mathrm{mL}$, respectively (Table 2 ). As shown in Table 3, RSD values for precision and repeatability were 0.76 and $1.46 \%$ respectively. Recovery of added codycepin ranged from 103.15 to $109.90 \%$, with RSD of $2.38 \%$.

\section{DISCUSSION}

The standard curve of cordycepin had very good linearity $\left(R^{2}>0.99\right)$. This shows that it is suitable for determination of cordycepin in the range of 0 $50 \mathrm{ug} / \mathrm{mL}$.

Table 1: Peak time, peak area and peak height of standard cordycepin chromatogram

\begin{tabular}{lccc}
\hline $\begin{array}{l}\text { Concentration of } \\
\text { cordycepin standard } \\
\text { solution }\end{array}$ & Peak time (min) & Peak area & Peak height \\
\hline 1 & 6.592 & 70 & 5.4 \\
2 & 6.590 & 133 & 10.2 \\
5 & 6.585 & 332.6 & 25.8 \\
10 & 5.567 & 709.2 & 54.7 \\
20 & 6.589 & 1280.1 & 96.6 \\
50 & 6.589 & 3383.9 & 257 \\
\hline
\end{tabular}

Table 2: Content of cordycepin in cordyceps recombinant rice

\begin{tabular}{|c|c|c|c|}
\hline Material & Peak time (min) & Peak area & $\begin{array}{c}\text { Cordycepin concentration } \\
(\mu \mathrm{g} / \mathrm{mL})\end{array}$ \\
\hline \multirow{3}{*}{$\begin{array}{l}\text { Brown Rice } \\
\text { Cordyceps culture } \\
\text { medium } \\
\text { Cordyceps }\end{array}$} & 6.463 & Not detectable & \\
\hline & 6.583 & 968.13635 & 14.13 \\
\hline & 6.582 & 177.38225 & 2.56 \\
\hline
\end{tabular}

Table 3: Precision, repeatability and recovery of the proposed method

\begin{tabular}{|c|c|c|c|c|c|c|c|c|}
\hline Precision test & $\begin{array}{l}\text { Number } \\
\text { Peak time (min) } \\
\text { Peak area } \\
\text { Mean peak area } \\
\text { RSD }\end{array}$ & $\begin{array}{c}1 \\
5.645 \\
1054.3\end{array}$ & $\begin{array}{c}2 \\
5.569 \\
1054.6\end{array}$ & $\begin{array}{r}3 \\
5.959 \\
1038.7 \\
10 \\
0\end{array}$ & $\begin{array}{l}4 \\
5.4 \\
104 \\
.25 \\
\%\end{array}$ & $\begin{array}{l}86 \\
3.2\end{array}$ & $\begin{array}{c}5 \\
5.969 \\
1047.9\end{array}$ & $\begin{array}{c}6 \\
5.981 \\
1062.8\end{array}$ \\
\hline $\begin{array}{l}\text { Repeatability } \\
\text { test }\end{array}$ & $\begin{array}{l}\text { Number } \\
\text { Peak time (min) } \\
\text { Peak area } \\
\text { Mean peak area } \\
\text { RSD }\end{array}$ & $\begin{array}{c}1 \\
6.091 \\
251.9\end{array}$ & $\begin{array}{c}2 \\
6.097 \\
248\end{array}$ & $\begin{array}{r}3 \\
6.142 \\
257.8 \\
2 \\
1\end{array}$ & $\begin{array}{l}4 \\
6.1 \\
25 \\
40 \\
\%\end{array}$ & $\begin{array}{l}68 \\
7.8\end{array}$ & $\begin{array}{c}5 \\
6.166 \\
254.7\end{array}$ & $\begin{array}{c}6 \\
6.176 \\
250.2\end{array}$ \\
\hline Recovery test & $\begin{array}{l}\text { Number } \\
\text { Peak time (min) } \\
\text { Peak area } \\
\text { Mean peak area } \\
\text { RSD }\end{array}$ & $\begin{array}{c}1 \\
6.009 \\
1083.1\end{array}$ & $\begin{array}{c}2 \\
6.041 \\
1074.5\end{array}$ & $\begin{array}{r}3 \\
6.05 \\
1042 \\
10 \\
2\end{array}$ & .82 & $\begin{array}{r}4 \\
6.0 \\
103\end{array}$ & & $\begin{array}{c}5 \\
6.085 \\
1017.9\end{array}$ \\
\hline \multirow[t]{5}{*}{$\begin{array}{l}\text { Recovery of } \\
\text { standard } \\
\text { addition }\end{array}$} & $\begin{array}{l}\text { Original } \\
\text { cordycepin content } \\
(\mu \mathrm{g})\end{array}$ & 1417.24 & 1418.65 & \multicolumn{2}{|c|}{1420.07} & \multicolumn{2}{|c|}{1419.78} & 1419.5 \\
\hline & $\begin{array}{l}\text { Standard } \\
\text { Addition }(\mu \mathrm{g})\end{array}$ & 50 & 50 & \multicolumn{2}{|c|}{50} & \multicolumn{2}{|c|}{50} & 50 \\
\hline & $\begin{array}{l}\text { Actual concentration } \\
(\mu \mathrm{g} / \mathrm{mL})\end{array}$ & 14.67 & 14.69 & \multicolumn{2}{|c|}{14.7} & \multicolumn{2}{|c|}{14.7} & 14.69 \\
\hline & $\begin{array}{l}\text { Measured } \\
\text { concentration }\end{array}$ & 16.13 & 16 & \multicolumn{2}{|c|}{15.52} & \multicolumn{2}{|c|}{15.36} & 15.16 \\
\hline & $\begin{array}{l}\text { Recovery } \\
\text { Mean recovery } \\
\text { RSD }\end{array}$ & $109.90 \%$ & $108.93 \%$ & \multicolumn{2}{|c|}{$\begin{array}{c}105.56 \% \\
106.41 \% \\
2.38 \%\end{array}$} & \multicolumn{2}{|c|}{$104.49 \%$} & $103.15 \%$ \\
\hline
\end{tabular}


Results obtained in the determination of codycepin concentrations in culture medium and recombinant rice indicated that the high temperature extrusion method did not affect their codycepin concentrations, nor did it affect the stability of codycepin. The RSD of the precision test for the determination of cordycepin was 0.76 $\%$ (i.e., < $10 \%$ ), which indicates that the measured value was very close to the actual value. It also implies that the HPLC method has a high degree of precision.

In the repeatability test, RSD was $1.46 \%$ (i.e., < $10 \%$ ), indicating that standard deviation between the individual values of the same sample was very small. Thus reproducibility of the results is good.

Ideally, recovery should be close to $100 \%$. However, due to the nature of samples and reagents, interference from impurities and operating errors, standard recovery in the range of range of $90-110 \%$ is acceptable. In this study, mean recovery was $106.41 \%$, illustrating that recovery of added cordycepin was accurate and in accordance with analytical requirements.

\section{CONCLUSION}

The findings of this study demonstrate that analysis of cordycepin in recombinant rice with reversed-phase high performance liquid chromatographic method is feasible, fast, reliable and reproducible. Thus, the method is suitable for the determination of cordycepin content of artificial Chinese caterpillar fungus culture medium and recombinant brown rice.

\section{DECLARATIONS}

\section{Acknowledgement}

The financial support provided by Cereal Industry Public Welfare Research Foundation of China (no. 201313011-5) is greatly appreciated.

\section{Conflict of Interest}

No conflict of interest associated with this work.

\section{Contribution of Authors}

The authors declare that this work was done by the authors named in this article and all liabilities pertaining to claims relating to the content of this article will be borne by them.

\section{REFERENCES}

1. Shonkor Kumar D, Mina M, Akihiko S, Mikio S. Medicinal uses of the mushroom Cordyceps militaris. Current state and prospects. Fitoterapia 2010; 81(8): 961-968.

2. Wong J, Wang $\mathrm{H}, \mathrm{Ng} \mathrm{T}$. A haemagglutinin from the medicinal fungus Cordyceps militaris. Biosci Rep 2009; 29(5): 321-327.

3. Liu JP, Wang YC, Yong LI, Jia JM. Content Determination of Cordycepin in Fermented Cordyceps militaris by RP-HPLC. China Pharm 2011; 22(47): 44834484.

4. Shrestha B, Zhang W, Zhang $Y$, Liu X.The medicinal fungus Cordyceps militaris: Research and development. Mycol Prog 2012; 11(3): 599-614.

5. Jiang MZ. Extraction and Purification of the Polysaccharides of Silkworm Cordyceps militaris Fruiting Body and Rice Culture Medium. J Anhui Agric Sci 2010; 38(18): 9538-9539.

6. Reis FS, Barros L, Calhelha RC, Cirić A, Griensven LJLDV, Soković M, Ferreira ICFR. The methanolic extract of Cordyceps militaris (L.) Link fruiting body shows antioxidant, antibacterial, antifungal and antihuman tumor cell lines properties. Food Chem Toxicol2013; 62(6): 91-98.

7. Liu S, Sun $Q$, Gong $H$. Extraction and measurement of cordycepin from Chinese caterpillar fungus. J Dalian Polytech Univ 2013; 32(5): 320-324.

8. Wu FC, Chen YL, Chang SM, Shih IL. Cultivation of medicinal caterpillar fungus, Cordyceps militaris (Ascomycetes), and production of cordycepin using the spent medium from levan fermentation. Int $\mathrm{J}$ Med Mushrooms 2013; 15(4): 393-405.

9. Shrestha UB, Bawa KS. Economic contribution of Chinese caterpillar fungus to the livelihoods of mountain communities in Nepal. Biol Conserv 2014; 177(177): 194-202.

10. Wu JY, Leung HP, Wang WQ, Xu C. Mycelial fermentation characteristics and anti-fatigue activities of a Chinese caterpillar fungus, Ophiocordyceps sinensis strain Cs-HK1 (Ascomycetes). Int J Med Mushrooms 2014; 16(2): 105-114.

11. Ying WY, Alice $M$, Ruth $D$, Adeline BB, Meijer $H A$, Clemens MJ, Moor $\mathrm{CH}$, De. Cordycepin inhibits protein synthesis and cell adhesion through effects on signal transduction. J Bioll Chem 2010; 285(4): 2610-2621.

12. Wang $L$, Zhong S, Fang $X$, Wang J. Review of Cordyceps Polysaccharide Studies. J Microbiol 2003; 23(1): 43-45.

13. Zhuang H, Tao F, Jin Z, Xie Z, Xu X, Ming G, Bai Y. Effect of extrusion parameters on production process and expansion ratio of reformed rice. Trans Chin Soc Agric Eng 2011; 27(9):349-356.

14. Jiang FF, University $Y N$. Experiment on Content Determination of Adenosine and Cordycepin from Wild Aweto in Qiaojia County of Yunnan Province by HPLC. Anim Husb Feed Sci 2014; 35(6): 10-12.

15. Mao XL, Zheng GD, Zhang C, Guo XL. Determination of adenosine, cordycepin, and inosine in Cordyceps

Trop J Pharm Res, October 2016; 15(10): 2238 
Wang et al

sinensis by RP-HPLC. Cent South Pharm 2009; 7(12): 895-897.

16. Deng L, La-Ping HE, Qiu-Ping LI, Jing-Peng LI, Cui B. Optimization of Twin-screw Extrusion Process of
Composite Grains-rice. Acad Period Farm Prod Process 2013; 7(4): 28-29. 